\title{
COMPENSATING FOR THE IMMATERIAL. A LEXICAL AND SEMANTIC ANALYSIS OF
} AMERICAN BANK SLOGANS

\author{
Bogdan Veche \\ Department of Marketing and International Business Relations, Faculty of Economics and \\ Business Administration, Timişoara, Romania \\ bogdan.veche@e-uvt.ro
}

\begin{abstract}
The aim of this paper is to conduct a lexical and semantic analysis of bank slogans in order to shed light on how the immaterial character of financial services as well as the channel of communication - in this instance the Internet - influence the choice of vocabulary. We chose to focus on the case of the United States of America as there is an online index of over five thousand existing banks with links to their websites if they have a presence online. This allowed us to create a database of over fourteen hundred slogans from as many banks. The methodology, described in the first part of the study, relies on empirical research and content analysis with the help of online tools used to generate a word count based on our sample. The results obtained were presented as bar charts showing groups of words and their number of occurrences in descending order. This allowed to highlight meaningful word clusters and to identify the lexical and semantic patterns of American bank slogans. The findings reveal a small cluster of words (including determiners, conjunctions and prepositions) with an occurrence rate superior to $1 \%$, sufficient, however, to establish the main semantic patterns further supported and enriched by the analysis of two more clusters $(0.5 \%-1 \%$ and $0.2 \%-0.5 \%)$. It becomes apparent that, through this form of asynchronous communication, American banks seek to compensate for the immateriality of the service provided by using slogans which help establish their identity within the community they serve and humanize the banking experience through the creation of a meaningful relationship with their (potential) customers.
\end{abstract}

Keywords: slogan; online advertising; American banks; lexical analysis, semantic analysis.

JEL classification: $G 21 ; M 37 ; Y 80$.

\section{General Introduction and Methodology}

The aim of this paper is to provide a lexical and semantic analysis of the slogans of American banks based on the premise that the particular nature of financial services has a direct impact on the vocabulary used. Indeed, researchers emphasized that financial services and products are immaterial (Paviot, 1995), somewhat vaguely defined and of intangible quality. In turn, this would limit the "levels of consumer involvement, excitement, symbolism, or emotions" (Stevenson, 2012). Instead, the purpose of the appeal is to emphasize the bankers' professionalism and know-how in order to establish trust: "La communication bancaire doit axer son message sur le savoir-faire et prouver que l'on peut faire confiance aux banquiers. Elle doit procurer des symboles tangibles: faire que le service soit compris, avoir de la continuité et promettre ce qui est possible." ["Banking communication must focus on the know-how and prove that bankers can be trusted. It must provide tangible symbols: to make sure that the service is understood, to have continuity and to promise what is possible."] (Paviot, 1995: 104)

As for online advertising, it is an asynchronous form of communication, where the message is activated individually at the moment of reading (Lazović, 2014 apud Janoschka, 2004: 2). Given its specificity, online advertising, while borrowing from traditional forms of advertising, 
has to develop its own communication strategies. Indeed, the contact between the (potential) customers and the bank is established indirectly, while communication is onesided, i.e. virtually monologue-based, with the webpage visitor as the silent recipient of the displayed content. Therefore, the appeal must create immediacy while enhancing persuasion through the characteristics specific to slogans in general: attentive value, memorability, readability and selling power (Ke \& Wang, 2013: 276). Bank slogans in particular rely on evaluative lexical items, as they transmit, implicitly or explicitly, what is good, so as to draw attention to the bank's "importance, competitiveness, international role, innovation capacity, tradition, customer focus, etc." in an effort to "stress more or less overtly [its] higher level of goodness in comparison with other financial institutions" (Malavasi, 2007: 177). The vocabulary is therefore going to be marked by favorable connotations and a preference for keywords that trigger positive associations. The most common parts of speech used to that end are the noun, the adjective and the verb. The question then is to what extent the immaterial, intangible attributes of financial services are going to be catalysts for lexical diversity in an attempt to compensate for the lack of proper contact between the potential customers and the bank.

The list of slogans used for the present analysis was created based on the Bank Branch Locator - Online U.S. Banks \& Branches Locator, a database containing "5275 local and national banks offering banking services in United States with nearly 83000 branches in 10182 cities" (List of All Banks in U.S., 2021). The database does not provide direct access to the slogans themselves, but to the banks' websites and to their logos (which sometimes contain the slogans as well). This made it possible to build a list of 1411 bank slogans from 1401 local banks (having branches in no more than three, and most of the time, neighboring, states) and 10 national banks. This led to an almost tenfold increase of our existing database used for a cultural analysis of American financial slogans (Veche, 2018). We need to mention that we chose to take into account as separate entries slogans shared by several unrelated banks, with no differences in wording as, in our opinion, this reinforces lexical patterns and highlights key preferences. We also chose to regard as slogans short sentences of the type "Est. / Established...", "Since..." and "Founded..." followed by the year or the number of years, as these are statements pertaining to the banks' experience and ability to stand the test of time, which in turn is associated with reliability.

To perform a text analysis of the word frequency we sampled several free online utilities and chose "Text Analyzer" provided by Online Utility (Adamovic, 2009), which also identifies and displays the most frequent phrases in a body of text.

\section{Analysis and Results}

The 1411 slogans are based on 789 different words (items which are part of the same word family count separately). Their distribution according to the rate given by the number of occurrences is presented in Figure 1. 
Figure 1: The word rate.

The results show a preference for a cluster of words - only eighteen (roughly $2,28 \%$ of the database) - with a distribution superior to $1 \%$ and exceeding $5 \%$ in only one instance. They are shown in Figure 2.

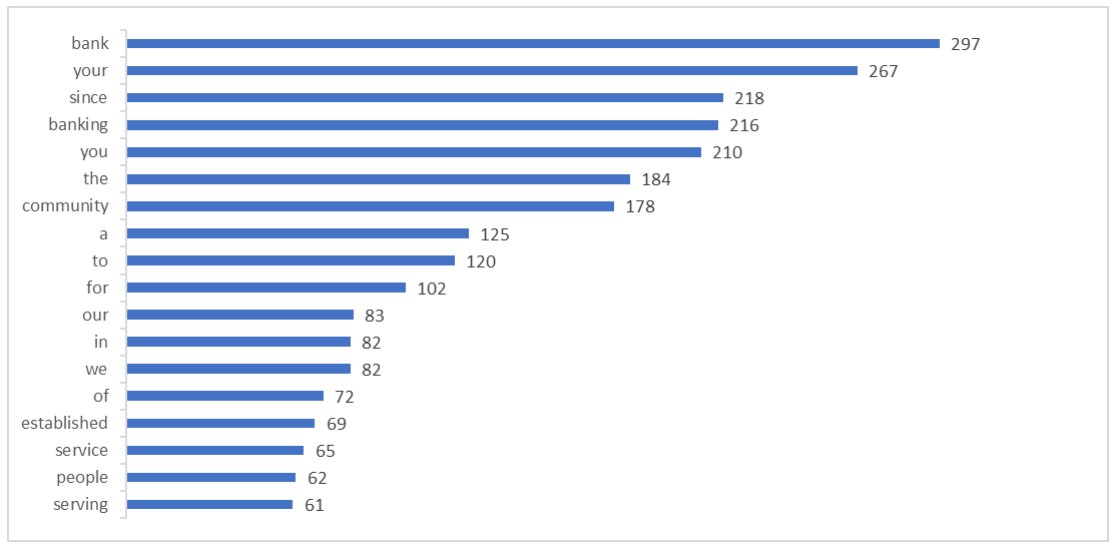

Figure 2: Words with an occurrence rate superior to $1 \%$.

Unsurprisingly, the word with the highest number of occurrences is "bank", used mostly as a noun (The Bank Your Bank), but also as a verb in a significant number of slogans (Bank On Us!), when not as both in the same sentence - compulsively, we might add (Bank With A Bank You Can Bank On!). Clearly, when a noun, its main purpose is to identify the reality (i.e., the financial institution) behind the services offered, thus giving weight to an otherwise immaterial entity since the contact with the customer is established online. As a simple verb, it may either serve the same purpose, when used with the meaning of "putting money in a bank" (Bank with $B o B$ ), or it conveys the idea of "dependability" / "reliability" when used as a phrasal verb (You can bank on us!). Not far behind, with 216 occurrences, "banking" is used to the same effect (Banking the way it should be).

The determiner "your", ranking second, and the personal pronoun "you", ranking fourth, express possession and thus create a subtle bond between the bank and the potential customers, or reinforce an existing one with current customers. Whether a relationship catalyst or reminder, both the possessive adjective and the personal pronoun establish "communicative immediacy" as "online bank advertisements generally try to involve users in the communication process" (Lazović, 2014: 96), not without flattering them, since both forms shift the focus on the recipient of the message (It's your bank! / Your bank. For life. I Taking you into account / You matter to us). 
Because most of the banks in our list are local and "bank services and products are marketed at a domestic audience" (Lazović, 2014: 91), their existence and purpose and those of the community they serve are deeply intertwined. It is therefore not surprising that the noun "community" is one of the most frequently used. It suggests proximity and camaraderie, while also giving a sense of belonging. The bank then ceases to be an "outsider" and becomes a community member with the same stakes as the rest, while very often its financial nature is not even mentioned (Partners in the Community / Putting the Community First / Strength. Service. Community. / The Community Advantage / This is Your Community. This is Your Bank. / Where Community is First!).

The pronoun "we" (82 occurrences) and the possessive "our" (83 occurrences) are used to "populate" the otherwise rather abstract entity called "bank". The customer perceives behind them the work of a team of people, which increases trust as it "humanizes" the financial institution and makes it resemble any other company (Doing what we promise). At the same time, this is often done to suggest cooperation (Together We Can / Together We Grow / United We Stand! / We Are One) and a mutually beneficial partnership with a common goal (Together we'll find a way / We grow by helping others grow!), although the bank usually plays second fiddle (We Make Banking About You / We Revolve Around You / We promise to walk in your shoes).

A similar goal is achieved by the express use of the shortlisted word "people", which gives weight to the financial service as its existence is possible, for the brick-and-mortar banks at least, only through human interaction. From this perspective, slogans including this word can be divided into those focused on the staff (Good People. Strong Values / Our People Care. It's Our Promise. I Our People Make The Difference.) and those focused on the customer valued as an individual and a human being, which in turn humanizes the service (Because people are more valuable than money / Investing in People / It's all about people!). A feeling of closeness and familiarity is induced by the slogans of some local banks serving a small community (It's nice to work with people you know!), with a touch of professionalism (People who know banking People who know you). It is noteworthy that the words "people" and "community" are very frequently included in the banks' names ("People's Bank" I "Peoples Bank" / "Community Bank").

As mentioned above, we chose to include in the list of slogans the preposition "since" and the adjective "established", followed by the year the bank was created. Because most of the time they are part of the logo itself, they reinforce the identity of the bank. The idea suggested is that of strong tradition and longevity, which the customer further interprets as professionalism, reliability, and stability. Another feeling derived is that of trust, which is important when it comes to someone's financial transactions, savings or long-term deposits. For banks, attempting to exude trustworthiness is paramount, especially as over the past decades, confidence in financial institutions has declined due to crises. Faced with image problems, they try "to restore trust and retain it by offering safety, security and reliability [...]" (Lazović, 2014: 92). Furthermore, "established" also conveys the idea of respectability for having stood the test of time (Cambridge University Press, 2019). The message is either short and straightforward (Since 1852 / Established 1934), or included in a longer slogan, as part of the same sentence or as a separate one (Getting it done since 1848 / Established 1904. Strength. Integrity. Stability). The preposition "for", followed by the amount of time during which the bank has been operational, serves the same purpose (Heritage And Experience For 75 Years / Locally Owned for over 117 years!).

Last but not least, banking is about "service" and words such as this noun itself and the present participle "serving" are reminders of that. Presenting itself as an intermediary between the customers and their goals while providing expertise and the financial means for that goal to be reached, the bank adopts a humble stance, while suggesting a relentless and usually long-term effort in supporting its clientele. If, sometimes, through the slogan, the bank introduces itself as a service provider by addressing the individual customer 
directly (Serving You Since 1902 / Sixty Years, Serving You / Serving you is our life's work.), most of the time it uses the opportunity to make it clear that its purpose is to serve and provide financial support to a community or to the inhabitants of a particular area (Serving Our Rural Communities Since 1884 / Serving the Community Since 1917/ Serving this area since 1906 / Serving the Hill County Since 1908 / Serving Montana's Finest Since 1960).

While we have deliberately ignored the definite article and the prepositions which simply help build the phrases with little or no impact on their meaning, the analysis of the words most often used in American bank slogans manages to establish a discernible pattern. First of all, there is a need to name the entity and its intangible products ("bank" and "banking") and to show that its existence - very often long-lived ("since..." and "established...") - is owed to and dependent on the customer or a community and their financial needs ("you" and "your"; "community"). The bank's purpose is therefore to "serve", and for that the entity must efface itself in favor of the human element ("we" and "our") since the transactions are done by and for "people".

While the number of occurrences dwindled rapidly from one word to the next in the previous figure, it only decreases gradually for the rest of the words in the list and, although the rate of appearance is under $1 \%$, it is worth investigating whether they support the previous pattern. Obviously, an exhaustive analysis would exceed the limits of the present paper, yet we will present briefly relevant details. For a clearer perspective, the group of words with an occurrence rate between $0,5 \%$ and $1 \%$ is presented in Figure 3.

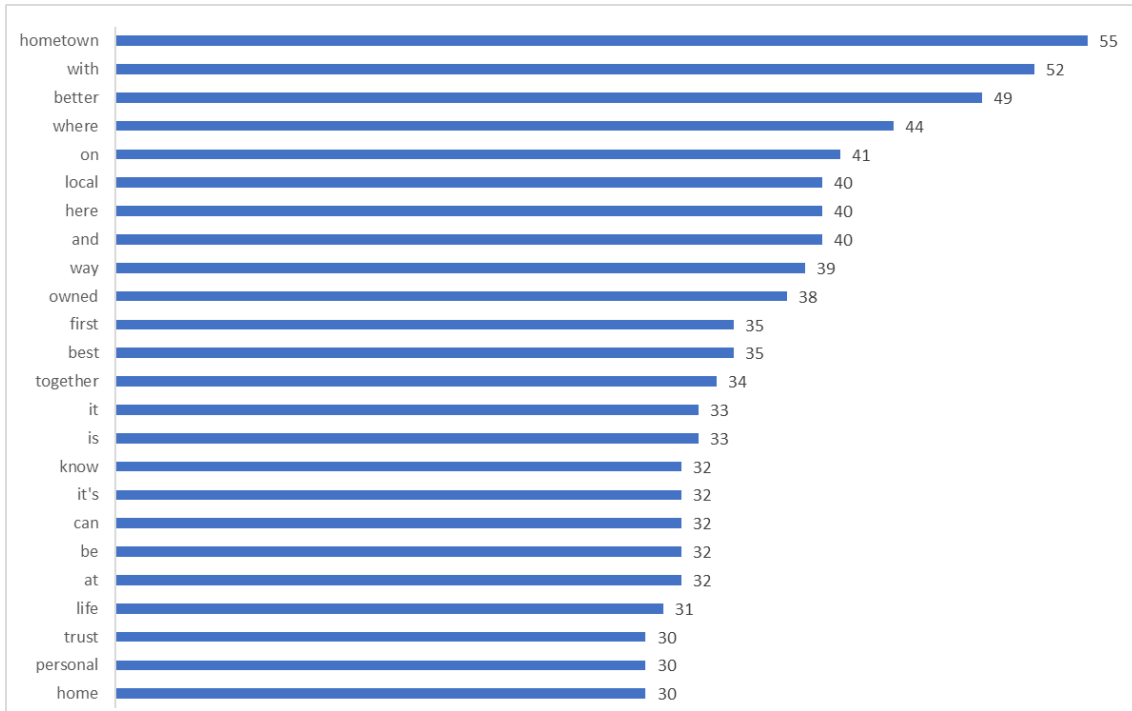

Figure 3: Words with an occurrence rate ranging from $0,5 \%$ to $1 \%$.

Several details stand out from the very beginning. The fact that most banks operate locally instead of nationally translates into a limited use of power words and even when used, "better", "best", and "first" are, in most cases, about the customers or about their banking experience (Life's Better When We're Connected / For a Better Way of Life / In Your Best Interest. / Your best friend in banking. / Putting People First / Where Community is First!). Instead, the slogan favors words suggesting closeness, reliability, and trust. Unsurprisingly, at the top come "hometown" (Hometown Banking!/ Your Hometown (Financial) Advantage / Banking With A Hometown Touch!) and the adjective "local" (Local. Not Limited. / Keeping it local / True Local. True Banking / It's A Local Thing) - in one instance enough to make the entire slogan (Local.). Sometimes, the former further circumscribes the activity to a certain town - also "home" to both the bank and the inhabitants, thus evoking familiarity to 
the customer (Home Owned. Home Operated. Home Town. / Home Style Service / The Home Folks). Therefore, "hometown" is on par with "community" since sharing the living area with the customers equals being closer to them and directly involved in their daily routine. The adverb "together" is often used to reinforce the banks' involvement through a customer-oriented approach or as promoters of inclusive growth (Working Together For You / Doing great things together / Pulling Together For You... / Growing Prosperity Together). Many of these local banks are "here", acting like a reassuring presence that guarantees financial security. This is particularly effective in the case of financial institutions with a long tradition in a certain area or interested in conveying a sense of long-term commitment to supporting the community (We're Here On Your Account Since 1889 / Since 1851. Life is what you make of it. We're here to help. / Traditional banking that's here to stay! / Here for good. / Here with you / Here for You. Every Day.). As such, the bank is a familiar presence, well-known and implicitly trustworthy, hence the frequency of the verb "to know" (Community People You Know / You Know Us We Know You! / The people you know.) and of the word "trust", used either as a noun or as a verb (Strength. Trust. Community. / Relationships. Solutions. Trust. / People You Know. People You Trust. / Banking You Can Trust.). In such a context, a merely utilitarian view of banking is out of place and most slogans aim to limit this perspective. The banking service is part of most people's lives and achieving financial security is a long-term process, which is why the use of the noun "life" as a reminder of this - sometimes with a prescriptive attitude (Spend Life Wisely) - as well as a guarantee for lasting support, does not come as a surprise (Family. Business. Life. / Helping Members... Build a 'Wonderful Life' since 1887 / for wherever life takes you / Growth. For You. For Life.). It is the reason why some of them revolve around the adjective "personal" used in an effort to humanize the banking experience as well as to suggest the local banks' genuine commitment to the local community to which their staff often belong as well (Personal Friends, Personal Bankers / Personalized Service From People You Trust / To us, it's personal. Serving the community since 1912 / It's not just business. It's personal. / The Bank of Personal Service).

Finally, we chose to include another set of words (Figure 4), with an occurrence rate inferior to $0,5 \%$ and superior to $0,2 \%$ (at a limit of 14 occurrences), which keep reinforcing the previous pattern. 


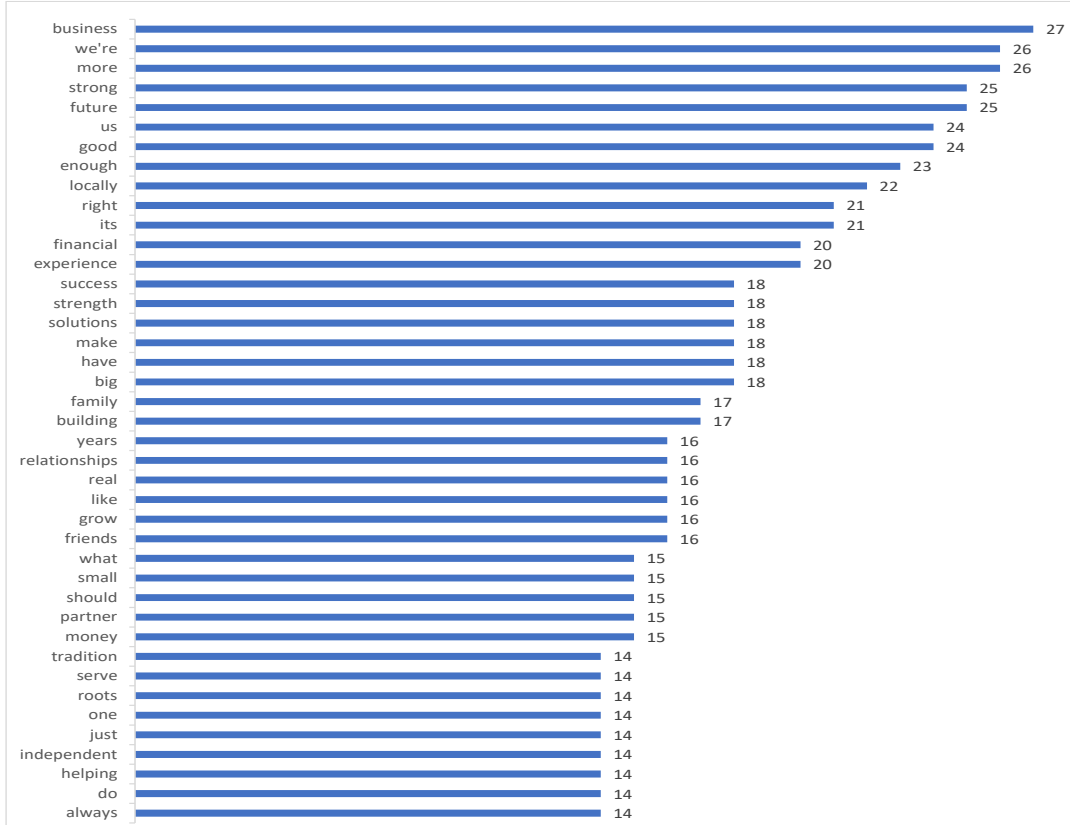

Figure 4: Words with an occurrence rate $<0,5 \%$ and $>0,2 \%$ (with a limit of 14 occurrences).

At the top of this list, "business" is only three occurrences short from being included in the previous one. In some instances, it is needed to narrow down the activity to business banking, in which case it is used alone (The Bank Business Banks On / Banking Built for Your Business), while in others it is used alongside other terms which emphasize the bank's devotion to its customers, their needs and interests (We Take Your Business Personally), as well as to create a sense of closeness (We do business right here at home / Where business and friendships meet).

What is obvious is that most of these words can be grouped according to the general meaning to be conveyed. "Financial" and "money" represent the banks' core activity, so they are inevitable. However, since banks are a common presence everywhere, most slogans attempt to incorporate them creatively (Long Live Your Money, Nice People with Money) and often in conjunction with metaphors (Your financial bridge / Your Financial Outfitter / Your Financial Cornerstone). The trustworthiness, reliability and profitability of banking activities and services are paramount and therefore well represented in this group as well: "tradition" / "roots" (A Tradition of Trust / We have our roots where others have their branches), "future" / "years" / "always" (Where Your Future Shines / 100 Years. 100 Reasons. I Always there / Always Within Reach), "experience" (People You Know. Experience You Trust.), "success" (Success. Together. / Success has a bank), "strength" I "strong" (Financial Strength In Local Hands. / Aim High. Bank Strong.), "good", "right", "big" (The Bank that's Good as Gold / Here for good. / Right By You / Bank in the right direction / Small in Size, Big on Service / We're Big on YOU), "partner" (Partners in Your Vision. I Your Partner For Life). Another group reinforces the already well-represented idea of closeness and familiarity that gives identity to local banks as actual members of the communities in their respective areas: "family" / "relationships" / "friends" (Friend of the Family Since 1899 / We treat you like family / banking on relationships / Earning Relationships / You're Banking with Friends). 


\section{In conclusion}

The fact that the lexical and semantic analysis allowed for such clearly discernible patterns supports the idea that, indeed, bank slogans need to compensate for the immateriality of the services provided by instantly establishing a meaningful connection with the recipient of the message. Surprisingly, the sampled slogans rely on the clever use of only a limited number of words with a significant number of occurrences, while addressing a two-pronged challenge: to properly carve out an identity for an otherwise immaterial entity operating in a competitive landscape, while defining the relationship with its customers - often at an individual level - through an approach meant to humanize the banking experience.

\section{References}

1. Adamovic, M. (2009, December). Text Analyzer - Text Analysis Tool. Retrieved January 24, 2021, from Oline Utility: https://www.online-utility.org/

2. Cambridge University Press. (2021). English Dictionary, Translations \& Thesaurus. Retrieved from Cambridge Dictionary: https://dictionary.cambridge.org/

3. Janoschka, A. (2004). Web Advertising. New forms of communication on the Internet. Amsterdam/Philadelphia: John Benjamins Publishing Company.

4. Ke, Q., \& Wang, W. (2013, February). "The Adjective Frequency in Advertising English Slogans.", Theory and Practice in Language Studies, 3 (2), 275-284. doi:http://dx.doi.org/10.4304/tpls.3.2.275284

5. Lazović, V. (2014). “The language of online bank advertisements in English.”, ESP Today, 2 (1), 88104. Retrieved February 15, from https://www.researchgate.net/publication/293760700 The language of online bank advertisement $\mathrm{s}$ in English

6. List of All Banks in U.S. (2021, April 11). From Bank Branch Locator - Bank Locations in US: https://www.bankbranchlocator.com/

7. Malavasi, D. (2007). "Lexical Analysis of Implicit Promotional Devices in Bank Annual Reports", ILCEA(9). doi:10.4000/ilcea.724

8. Paviot, G. (1995). "La communication publicitaire et la réputation des banques", Communication et langages (105), 92-104.

doi:https://dx.doi.org/10.3406/colan.1995.2617

9. Stevenson, R. (2012, February 20). Top Five Challenges of Financial Services Marketing. Retrieved February 15, 2021, from Snap! Adventures in Financial Marketing: https://stevensonfinancialmarketing.wordpress.com/2012/02/20/top-five-challenges-of-financial-

services-marketing/

10. Veche, B. (2018, July). "A cultural analysis of financial slogans. The case of US banks and credit unions.", The Annals of The University of Oradea. Economic Sciences, XXVII(1), 363-374. Retrieved February 13, 2021, from http://anale.steconomiceuoradea.ro/volume/2018/AUOES-1-2018.pdf 